\title{
Modelling to evaluate agricultural adaptation to climate change in southern Australia
}

\author{
Robert Farquharson a , Amir Abadi ${ }^{\text {b }}$, John Finlayson ${ }^{\text {c }}$, Thiagarajah Ramilan ${ }^{\text {d }}$, De Li Liu ${ }^{\text {, }}$ \\ Muhuddin Anwar ${ }^{\mathrm{c}}$, Steve Clark ${ }^{\mathrm{e}}$ \\ ${ }^{a}$ Melbourne School of Land \& Environment and Future Farm Industries Cooperative Research Centre \\ ${ }^{b}$ Department of Parks and Wildlife Western Australia and Future Farm Industries Cooperative Research \\ Centre \\ ${ }^{c}$ NSW Department of Primary Industries and E.H. Graham Centre, Wagga Wagga \\ ${ }^{d}$ International Crops Research Institute for the Semi-Arid Tropics, Patancheru, India \\ ${ }^{e}$ Victorian Department of Environment and Primary Industries, Hamilton \\ Email: bob.farquharson@unimelb.edu.au
}

\begin{abstract}
An important issue for Australian agriculture is the capacity to adapt to predicted climate change. The International Panel on Climate Change (IPCC) (2009) refers to adaptation as 'adjustment in natural and human systems in response to actual or expected climate stimuli or their effects, which moderates harm or exploits beneficial opportunities'. Conceptualizing and evaluating adaptation options in agricultural industries should be conducted at the farming systems level (Rickards et al. (2012), Hayman et al. (2012)) because it is at this level that management decisions are made and financial as well as natural resource impacts will be felt. In particular whole-farm analysis can represent purposeful, goal-seeking systems (Dillon 1976) to assess farmers' profitability and the system's sensitivity to risks such as climate variability and change. The potential of Australian dryland agricultural systems to adapt to climate change with perennial plants was assessed by Farquharson et al. (2013). Perennial plants have deeper rooting systems with improved access to soil moisture, making them better suited to warmer and drier climates. Climate data were generated using Global Circulation Models (GCMs) downscaled to specific locations and corrected for bias (Liu and Zuo 2012). The climate data were used to estimate growth and yield of grain crops, pastures, and an energy-tree crop using process models such as APSIM (McCown et al. (1996)) and GrassGro (Moore et al. (1997). Plant yield and production estimates and economic data (prices of inputs and commodities) were used in bio-economic models (MIDAS (Kingwell and Pannell 1987) and IMAGINE (Abadi and Cooper 2004)) to identify the most profitable land use and the cash flow of options available to growers.
\end{abstract}

The general result was that adaptation to climate change using new perennial plants shows promise (at least in the short term) of maintaining the economic condition of these dryland farming systems.

While simulation of future conditions is necessary to develop model parameters, we argue that to properly evaluate adaptation a constrained optimising approach is both necessary and sufficient. Adaptation of farm enterprises in a commercial farming system needs to account for the opportunity costs of alternative land uses. To accomplish this, it is necessary to develop bio-economic models with capacity for optimization. Linear Programming (LP) models were used which account for limited or constrained physical, biological and financial resources (e.g. labour, land, credit and time). With the objective function of profit maximization such models explicitly account for opportunity costs faced by decision makers (Paris 1991). The Marginal Value Product (MVP) of each farm activity is the value that the last few hectares contributes to the objective function, and is the basis for the revised farm plan that develops the adapted pattern of farm activities. The adapted farm plan is then used to conduct cash flow analysis which considers the likely risk (income variation) associated with future activities compared to the past.

The use of constrained optimisation is the appropriate way to assess adaptation for purposeful decisions because it accounts for the opportunity costs of farming system decisions - this is the economic evaluation of adaptation. The analysis of farm system components in terms of cash flows considers financial aspects of adaptation. Modelling is essential in assessing future responses to changed external conditions, but constrained optimisation is additionally required to evaluate economic adaptation to climate change in future farming systems.

Keywords: farming systems, climate change, economic, adaptation, linear programming 


\section{INTRODUCTION}

Adaptation to climate change is an important issue for dryland agricultural industries in Australia. The predicted effects of climate change are for higher temperatures, reduced rainfall and changed ambient $\mathrm{CO}_{2}$ levels. Allied with this is the existing situation for Australian agriculture where farmers operate in a small open economy with around $80 \%$ of agricultural produce exported with farmers being price takers in export markets (Productivity Commission 2009). Terms of trade pressures on Australian farmers have traditionally been offset by improved productivity (Dahl et al. (2013)). The question is whether continued adoption of improved technologies or management can offset both adverse price movements and new plant production patterns under a changed climate.

Adaptation is defined by the (IPCC) (2009) as 'adjustment in natural and human systems in response to actual or expected climate stimuli or their effects, which moderates harm or exploits beneficial opportunities'. The Future Farm Industries Cooperative Research Centre (FFI CRC) (2012) has conducted research on the effects of new perennial plants on agricultural productivity under existing conditions, including agronomic evaluation of a new pasture plant, Tedera (see Finlayson et al. (2012)), and a coppicing eucalypt tree (mallee) grown for biomass (see Stucley et al. (2012)).

The potential for Australian dryland agricultural systems to adapt to climate change with perennial plants at four sites in southern Australia was analysed in Farquharson et al. (2013). In the present paper we discuss the modelling approach of that analysis and focus on the types of models that were used to answer the specific research questions. The major point of departure for Farquharson et al. (2013) was to apply economic optimisation modelling to test the capacity of novel perennial pasture plants, including woody crops for biomass, to transform whole-farm systems and enable adaptation to climate change. The farming system was optimised after accounting for changing resources of rainfall, land, labour and finance. Most previous assessments of the capacity of the farming system to adapt to predicted climate change have been based on assessing the impact of single components (enterprises) of the mixed farming system using existing suites of plants - this is effectively economic simulation. An example of this approach is Heyhoe et al. (2007). But constrained optimisation was used by Farquharson et al. (2013) and in this paper we discuss this approach as a rigorous and effective method of evaluating adaptation of farming systems with economic objectives.

\section{ANALYTICAL APPROACH}

\subsection{Research question}

The specific aim of the research of Farquharson et al. (2013) was to evaluate the extent to which dryland agriculture would incorporate novel perennial plant technologies and adapt to climate change, when economic outcomes were the primary objective. In particular perennial pastures have deeper rooting systems which may be better suited to warmer and drier climates due to improved access to soil moisture at depth. The approach was to model currently achievable innovations and their economic feasibility for large scale adoption under predicted climate scenarios for southern Australia. Two main effects were tested- the impact of climate change (historical climate versus a predicted climate) and the effect of additional perennials in farming systems (annual plant-based farming versus farming systems with additional perennials), see Table 1.

Table 1. Scenarios tested

\begin{tabular}{|l|c|c|}
\hline Assessed in current year terms & \multicolumn{2}{|c|}{ New perennial plants, shrubs and trees } \\
\cline { 2 - 3 } & Without & \\
\hline Historic Climate & $X$ & \\
\hline 2030 Dry Climate & $X$ & X \\
\hline
\end{tabular}




\subsection{Modelling framework}

A sequential consultation and modelling approach was used (Figure 1). Consultations with farmers, agricultural advisors and research workers at each site preceded the systems conceptualisation and analysis.

Predictions from one GCM - CSIRO Mk3.5 (S2), for the A2 emissions scenario (Nakicenovic and Swart 2000) were used. Predictions for daily minimum and maximum temperature and rainfall were downloaded and bias corrected (Liu and Zou 2012) for the CWB Cunderdin site. The S2 data for the above temperature series over the period 2012-2052 were used with historical (SILO) data over the period 1971-2011 to represent future and past climates. Annual rainfall is projected to decrease by $13 \%$ to 2030 and mean annual temperature is projected to increase by $1.2{ }^{\circ} \mathrm{C}$ to 2030 . The $\mathrm{CO}_{2}$ concentration used in plant modelling increased linearly from $380 \mathrm{ppm}$ in 2012 to $550 \mathrm{ppm}$ in 2050.

These data were input to APSIM and GrassGro to develop crop yields and plant production predictions for the scenarios in Table 1. The modeled plant yields were adjusted down to likely on-farm yields (Davidson and Martin 1965), which were used in the economic models.

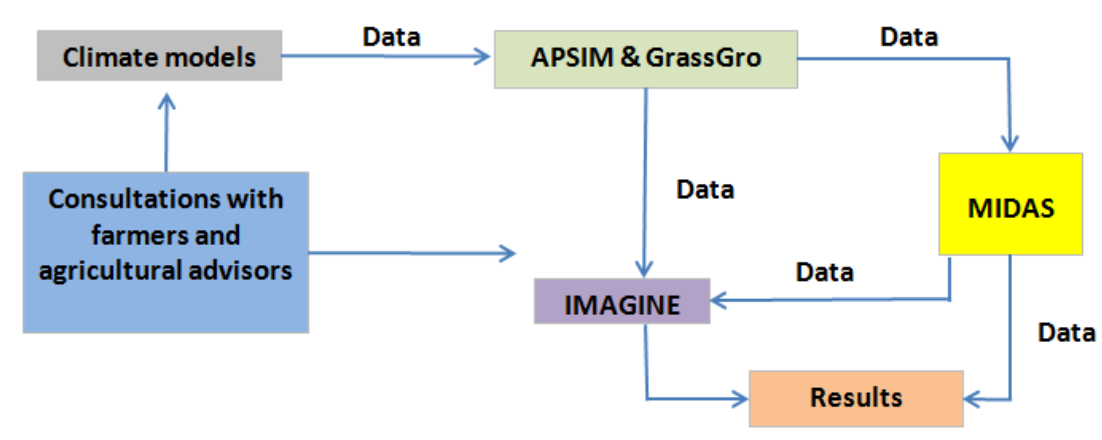

Figure 1. Modelling approach

\subsection{Consultations with farmers and advisors}

The conversations with farmers and advisors showed that farmers were capable of and willing to adapt to change, that the economic imperative was a very important objective, that they were looking to new technologies to help them adapt to climate change, and that they were not averse to a new activity such as alley farming with mallee trees for biomass as feedstock for biofuel production. In a social sense, these farmers seemed to be happy to continue to operate their business by adapting with continued help from agricultural R\&D. An example of a new technology in the climate change context is an agricultural plant with seasonal growth parameters which could utilise future climatic conditions.

\subsection{Plant model parameterization}

The APSIM and GrassGro models were specified for Cunderdin with key parameters given in Table 2.

Table 2. Key soil and plant model parameters at Cunderdin

\begin{tabular}{|l|c|c|}
\hline APSIM soils (Isbell 1996) & Soil depth (cm) & PAWC (mm) \\
\hline Acid loamy sand (Tenosol) & 250 & 78 \\
\hline High clay (Kandosol) & 250 & 123 \\
\hline Deep sandy duplexes (Sodosol) & 210 & Dalkeith sub-clover \\
\hline GrassGro: acid sand soil & Annual ryegrass & Senescent \\
\hline Phenology & Senescent & 0 \\
\hline Live Dry Matter (DM) (kg/ha) & 0 & 1000 \\
\hline Standing dead DM (kg/ha) & 1000 & 200 \\
\hline Litter DM (kg/ha) & 500 & 450 \\
\hline Max. rooting depth (mm) & 560 & 150 \\
\hline Seed DM (kg/ha) & 100 & \\
\hline
\end{tabular}


Farquharson et al., Modelling to evaluate agricultural adaptation to climate change in southern Australia

\section{ECONOMIC ANALYSIS FOR ADAPTATION}

\subsection{Necessary and sufficient conditions for assessing adaptation to climate change}

From the IPCC (2009) definition, the policy need is to test 'adjustment in natural and human systems in response to .. expected climate .. effects' which 'moderates harm or exploits beneficial opportunities'. In farming systems analysis the changes that occur in natural systems under a changed climate are likely to be reflected in biophysical (plant production) functions and these need to be managed by the human factor of farm management. Plant production varies, inter alia, according to changes in rainfall, temperature, solar radiation and $\mathrm{CO}_{2}$ levels.

The evaluation of adaptation opportunities involves both necessary and sufficient conditions (Chiang (1984), p. 89, Silberberg (1990), p.627). It is necessary to assess the likely bio-physical changes under a future climate, with climate and plant simulation model predictions. But to assess adaptation by humans, a management objective - such as profit - needs to be incorporated into a systems model. We argue that this is an extra or sufficient condition needed to adequately consider adaptation.

Implied in this statement is the need for farm system constraints to be included in the analysis. Firstly, there is the reality that farm managers must consider the limited supplies of resources available to them, and account for other constraints associated with crop-pasture rotations when making decisions. A restricted production possibility set exists. Secondly, the inclusion of these constraints in conjunction with the economic optimising solution procedure enables the true costs of resource usage to be accounted for - this approach explicitly accounts for opportunity costs.

A methodology which includes both the necessary and sufficient conditions is LP (Paris 1991, Pannell 1997), where both bio-physical and economic parameters are included and the objective of farm profit is constrained by resource availability. These are developed to be representative of farming systems.

\subsection{Whole-farm economic modelling}

MIDAS (Model of an Integrated Dryland Agricultural System) is a steady-state LP model of a farming system which accounts simultaneously for the biology and economics of the system (Kingwell and Pannell 1987). The objective function is whole-farm profit which is maximized subject to managerial, resource and environmental constraints. Profit is defined as net cash returns after non-cash costs (depreciation) and opportunity cost of capital (exclusive of land) are deducted. MIDAS is based on a typical (expected/average) season and excludes consideration of plant yield variability and extreme climatic events.

MIDAS models are steady state, meaning that production coefficients represent a time when production has stabilized, possibly after more than one rotational cycle. Dynamics are represented in the sense that production depends on land use and agronomic practices in the previous year, but not in the sense of tracking the move from one equilibrium to another. It is assumed that climatic conditions are 'average' every year.

For programming models such as MIDAS it is important to represent the farming system, with its array of production technologies, resources and enterprise alternatives, in some detail (Kingwell (1996)). Unless this occurs it is likely that specification errors will bias estimates of supply response.

The major strengths of MIDAS are its joint emphasis on biology and economics and its ability to address a range of whole-farm issues in a profit-maximizing framework. In particular MIDAS simultaneously considers the allocation of land to alternative enterprises, rotation selection, livestock flock structure and stocking rate, strategies for grazing and supplementary feeding, machinery size and pattern of use, and impact of limited finance on the optimal farm strategy.

MIDAS can also provide additional useful information such as the optimal rotations for each Land Management Unit (LMU) and the size and management of sheep flock and other economic indicators 
Farquharson et al., Modelling to evaluate agricultural adaptation to climate change in southern Australia

including the marginal value of resources such as labour, finance, seeding capacity, and livestock feed in each of ten periods. For a full description of MIDAS see Kingwell and Pannell (1987).

In this paper the results from Farquharson et al. (2013) for the Central Wheatbelt (CWB, at Cunderdin) of Western Australia are presented to illustrate discussion of appropriate modelling to answer questions of adaptation to predicted climate change.

\subsection{Marginal values for farm enterprises}

Optimizing models are able to provide information about the marginal value of resources. For example economic values can be determined for the last small amounts of land in the optimal solution. These are the MVPs of land (Paris (1991), Pannell (1997)) - they show the extra value that an additional unit of land could contribute to the objective function. The MVP is also termed the shadow price of each LMU.

The MVP of land is likely to vary according to the soil and topography characteristics, the area of each LMU, and associated crop yield and pasture productivity parameters. Changes in land use occur as climate and perenniality options are modified or added and these can be explained by changes in the MVPs. That is, the MVPs indicate the economic incentives to change within each component of the farming system. They can differ substantially according to the type of soil resource and associated agricultural productivity.

\section{ECONOMIC RESULTS}

The whole-farm economic results for the CWB are in Table 3. In the base solution (historical climate) the proportion of farm land is $75 \%$ to crops and $25 \%$ to pastures (Merino wool sheep), which accords with benchmarks for the region (Planfarm-Bankwest 2012). Annual pastures (sub-clover and annual ryegrass) are the basis for the Merino sheep enterprise. The stocking rate is 7 Dry Sheep Equivalents (DSE)/ha and 22 $\mathrm{kg} / \mathrm{DSE}$ supplementary feed is required during periods of shortage. Farm income is $\$ 110 / \mathrm{ha}$.

For one future climate without adaptation farm income falls to $\$ 89 /$ ha and there is no change in land use. When perennials (Tedera and mallee for biomass production) are included as management options farm income is raised back close to the former level and the pattern of land use is changed substantially to include perennials at the expense of crop. Interestingly annual pastures are still used and also increase in area. Associated effects on the wool enterprise are observed to be a slight reduction in stocking rate and removal of the requirement for supplementary feed.

Table 3. MIDAS whole-farm results for Cunderdin

\begin{tabular}{|c|c|c|c|c|c|c|c|}
\hline & \multicolumn{4}{|c|}{ Percentage of farm area (\%) } & \multirow{2}{*}{$\begin{array}{c}\text { Supp1* } \\
\text { Feed }\end{array}$} & \multirow{2}{*}{$\begin{array}{c}\text { Stocking } \\
\text { rate }\end{array}$} & \multirow{2}{*}{$\begin{array}{l}\text { Farm } \\
\text { profit }\end{array}$} \\
\hline & Crop & Annual & Perr. pasture & Mallee & & & \\
\hline & & pasture & (Tedera) & & $\mathrm{kg} / \mathrm{DSE}$ & DSE/ha & \$/ha \\
\hline \multicolumn{8}{|l|}{ Historical climate } \\
\hline Base & 83 & 17 & - & - & 22 & 7 & 110 \\
\hline \multicolumn{8}{|l|}{ S2Climate } \\
\hline Base (no Perennials) & 83 & 17 & - & - & 19 & 6 & 89 \\
\hline With Perennials & 53 & 30 & 18 & - & 0 & 6 & 104 \\
\hline With Perennials \& Mallee & 48 & 32 & 19 & 1 & 0 & 6 & 106 \\
\hline
\end{tabular}

* Supplementary feed is often a grain such as lupins fed out to sheep in stubble or dry pasture paddocks

The MVPs for farm activities (crop/pasture rotations) in the historical and future climate are in Table 4 (b). Under a future climate continuous pasture and mallee are the most profitable use of the poorer soils (LMU1acidic infertile sands, LMU2 - deep yellow brown loamy sands, LMU5 - red brown, sandy loam over clay subsoil). The significant difference between MVP of LMUs 1, 2 and 5 is due to their productivity - chemical and physical properties of the soils which affect their fertility and plant available water content resulting in strikingly different livestock carrying capacity of pasture. Crop rotations are the best use of the more agronomically productive soils where profitability of cropping outweighs that of livestock grazing of pastures. These include LMU3 - yellow brown gravelly soils and sandy gravels, LMU4 - grey sandy loams, 
Farquharson et al., Modelling to evaluate agricultural adaptation to climate change in southern Australia

loamy sands and sand over clay, and LMU6 - heavy non-friable clays. Tedera is grown in LMU8 - deep duplex soils, generally productive with good moisture and nutrient availability.

Table 4. Contributions to profit of land use on LMUs, Cunderdin

\begin{tabular}{|c|c|c|c|}
\hline LMU/Soil & Area (ha) & Profit contribution $(\$ /$ ha $)$ & Rotations selected and (area allocated) \\
\hline \multicolumn{4}{|c|}{ (a) Historic Base } \\
\hline 1 & 140 & 43 & Continuous pasture (140 ha) \\
\hline 2 & 210 & 120 & Wheat/Canola/Wheat/Lupin (210) \\
\hline 3 & 350 & 268 & Wheat/Canola/Wheat/Lupin (350) \\
\hline 4 & 210 & 171 & Canola/Wheat/Barely/Lupin (dry sown) (210 ha) \\
\hline 5 & 200 & 250 & Continuous pasture (200 ha) \\
\hline 6 & 200 & 230 & Wheat/Canola/Barley/Chickpea (200 ha) \\
\hline 7 & 300 & 147 & Wheat/Canola/Barley/Field Pea (300 ha) \\
\hline 8 & 390 & 224 & Wheat/Canola/Wheat/Lupin (390 ha) \\
\hline \multicolumn{4}{|c|}{ (b) Future with Perennials } \\
\hline 1 & 140 & 48 & Continuous pasture \& mallee (140 ha) \\
\hline 2 & 210 & 120 & Continuous pasture \& mallee (95 ha), Wheat/Barley/Lupin (115 ha) \\
\hline 3 & 350 & 258 & Wheat/Canola/Wheat/Lupin (350 ha) \\
\hline 4 & 210 & 173 & Wheat/Canola/Barley/Field Pea (210 ha) \\
\hline 5 & 200 & 236 & Continuous pasture \& mallee (200 ha) \\
\hline 6 & 200 & 237 & $\begin{array}{l}\text { Wheat/Canola/Barley/Field Pea (184ha), } \\
\text { Wheat/Canola/Barley/Chickpea (16 ha) }\end{array}$ \\
\hline 7 & 300 & 153 & 3 Pasture \& Wheat (300 ha) \\
\hline 8 & 390 & 234 & Tedera (373 ha), Wheat/Canola/Wheat/Lupin (17 ha) \\
\hline
\end{tabular}

\section{DISCUSSION}

The general policy conclusion from this work is that autonomous adaptation with plant perenniality appears to be possible for this dryland mixed farming system in the CWB of WA.

The focus of this paper is on methodology to adequately address adaptation according to the IPCC (2009) definition. We contend that bio-economic models representing farming systems with an economic objective function and resource constraints can best allow prediction of adjustments in natural and human systems in response to actual or expected climate stimuli, which moderate harm and exploit beneficial opportunities. Such information is important for policy makers and agricultural industries.

\section{CONCLUSION}

Modelling is essential for assessing plant responses to predicted climate change in farming systems. It is necessary to use simulation to predict these biophysical responses in a changed climate. We believe and demonstrate that the use of constrained economic optimisation models is both necessary and sufficient in evaluating adaptation according to the definition of IPCC (2009). 
Farquharson et al., Modelling to evaluate agricultural adaptation to climate change in southern Australia

\section{REFERENCES}

Abadi, A. and Cooper, D. (2004). A case study of the economics of alley farming with oil mallees in Western Australia using the IMAGINE framework. in Graham, T.W., Pannell, D.J. and White, B. (eds.), Dryland Salinity: Economic Issues at Farm, Catchment and Policy Levels. Cooperative Research Centre for Plant-Based Management of Dryland Salinity, University of Western Australia, Perth, Western Australia.

Chiang, A.C. (1984). Fundamental Methods of Mathematical Economics. McGraw-Hill, Singapore.

Dahl, A., Leith, R. and Gray, E. (2013). Productivity in the broadacre and dairy industries, Agricultural Commodities 3, 200-220.

Davidson, B.R. and Martin, B.R. (1965). The relationship between yields on farms and in experiments, Australian Journal of Agricultural Economics 9, 129-140.

Dillon, J.L. (1976). The economics of systems research, Agricultural Systems 1, 5-22.

Farquharson, R., Abadi, A., Finlayson, J., Ramilan, T., Liu, D.L., Anwar, M., Clark, S., Robertson, S., Mendham, D., Thomas, Q. and McGrath, J. (2013). EverFarm ${ }^{\circledR}$ - Climate adapted perennial-based farming systems for dryland agriculture in southern Australia, National Climate Change Adaptation Research Facility, . http://www.nccarf.edu.au/publications4, Gold Coast, pp 157.

FFI CRC (2012). About Future Farm Industries CRC, Perth, http://www.futurefarmonline.com.au/about/about-fficrc.htm.

Finlayson, J., Real, D., Nordblom, T.L., Revell, C., Ewing, M. and Kingwell, R. (2012). Farm level assessments of a novel drought tolerant forage: Tedera (Bituminaria bituminosa C.H. Stirt var. albomarginata), Agricultural Systems 112, 38-47.

Hayman, P.T., Rickards, L., Eckard, R. and Lemerle, D. (2012). Climate change through the farming systems lens: challenges and opportunities for farming in Australia, Crop and Pasture Science 63, 203-214.

Heyhoe, E., Kim, Y., Kokic, P., Levantis, C., Ahammad, H., Schneider, K., Crimp, S., Nelson, R., Flood, N. and Carter, J. (2007). Adapting to climate change, Australian Commodities 14, 167-178.

IPCC (2009). The IPCC Assessment Reports. http://www.ipcc.ch/publications and data/publications and data reports.shtml.

Isbell, R.F. (1996). The Australian Soil Classification. CSIRO Publishing, Melbourne.

Kingwell, R. (1996). Programming Models of Farm Supply response: The Impact of Specification Errors, Agricultural Systems 50, 307-324.

Kingwell, R.S. and Pannell, D.J. (1987). MIDAS, a bioeconomic model of a dryland farm system, Wageningen, $207 \mathrm{pp}$.

Liu, D.L. and Zuo, H. (2012). Statistical downscaling of daily climate variables for climate change impact assessment over New South Wales, Australia, Climate Change 3 May.

McCown, R., Hammer, G., Hargreaves, J., Holzworth, D. and Freebairn, D. (1996). APSIM: a novel software system for model development, model testing and simulation in agricultural systems research, Agricultural Systems 50, 255-271.

Moore, A.D., Donnelly, J.R. and Freer, M. (1997). GRAZPLAN: Decision support systems for Australian grazing enterprises. III. Pasture growth and soil moisture submodels and the GrassGro DSS, Agricultural Systems 55, 535-582.

Nakicenovic, N. and Swart, R., (eds.) (2000). Special Report on Emissions Scenarios. A Special report of Working Group III of the Intergovernmental Panel on Climate Change, http://www.ipcc.ch/ipccreports/sres/emission/index.htm.

Pannell, D.J. (1997). Practical Linear Programming. John Wiley and Sons, New York.

Paris, Q. (1991). An Economic Interpretation of Linear Programming. Iowa State University Press, Ames.

Planfarm-Bankwest (2012). Planfarm-Bankwest Benchmarks 2011/12. in Planfarm Pty Ltd (ed.), Wembley, Western Australia.

Productivity Commission (2009). Government Drought Support, Report No. 46, Final Inquiry Report, Melbourne.

Rickards, L., McKellar, R. and George, D. (2012). Climate Change Adaptation in the Australian Primary Industries: An Interpretative Review of Recent Literature (Draft), NCCARF National Climate Change Adaptation Research Plan.

Silberberg, E. (1990). The Structure of Economics, A Mathematical Approach. Englewood Cliffs, New Jersey.

Stucley, C., Schuck, S., Sims, R., Bland, J., Marino, B., Borowitzka, M., Abadi, A., Bartle, J., Giles, R. and Thomas, Q. (2012). Bioenergy in Australia - Status and Opportunities,, Bioenergy Australia (Forum) Limited, www.bioenergyaustralia.org, viewed 11 August 2013. 